\title{
The Degree of Physical Loads Characterization in the Exercises of Different Influence on Cadets' Organism During Airborne Training Lessons
}

\author{
Kuznetsova Z.M. \\ University of management "TISBI" \\ Naberezhnye Chelny, Russia \\ kzm_diss@mail.ru
}

\author{
Labeshchenkov O.V. \\ Tyumen Higher Military-Engineering Command \\ School (military Institute) \\ Tyumen, Russia \\ labeshenkova@yandex.ru
}

\begin{abstract}
The article is about the volume of the load in the exercises of different influence on cadets' organism in the content of different kinds of training. It is mentioned that taking into account the volume of the load according to its influence on an organism helps to control the mistakes, which are made during physical loads. The effectiveness of cadets' special parachute training depends on the following factors: real state of training level and cadets' readiness for the lessons revelation; qualitative time planning for airborne training (ABT) objectives realization; continuity of the received knowledge, abilities and skills during the lessons; systematic character of the knowledge, abilities and skills of personnel development in parachute jumps improvement and training for airdrop; physical loads of different orientation planning at the lessons; control organization at all stages of training; purposeful and constant ABT methodology development; modern technical means of training use.
\end{abstract}

Keywords-cadets; special parachute training; factors; degrees of physical load; exercises.

\section{INTRODUCTION}

Airborne training (ABT) of Tyumen Higher MilitaryEngineering Command School (military Institute) is the main subject of cadets' military training. The main aim of ABT is teaching cadets skills and abilities of airdrop in different conditions by means of parachute.

Modern conditions of teaching ABT subject demands ABT planning consideration not only during the lessons of theoretical orientation, but also the volume of the load according to the influence on an organism.

\section{LITERATURE REVIEW}

ABT specialists study the questions of cadets' sportstechnical mastery formation, intensification and development at military-educational establishments of engineering profile in terms of airborne training (O.V. Labeshchenkov). Eliseev S.A. (2017) considers the necessity to develop cadets' professionally-applied physical training at educational establishments of Federal security service (FSS) of Russia of the border profile as the base for competent specialist training.
Nesterovich S.N. $(2005,2008)$ underlines the necessity to increase the effectiveness of physical training improvement of FSS border authority military men in Russia in physicalgeographic and extreme conditions.

There are a lot of scientific works dedicated to the chosen topic. Military specialists of new formation, having a high level of technical knowledge, show insufficient level of the applied physical readiness, which is necessary in professional activity. The representatives of different kinds of sport also have insufficient level of physical readiness (O.M. Mirzoev, V.M. Maslakov, E.P. Vrublevskiy, 2007; S.N. Nesterovich, 2009, 2011; Kuznetsova Z., Kuznetsov A., Mutaeva I., Khalikov G., Zakharova A., 2015; A. V. Chaban, Z. M. Kuzneczova, A. V. Ryabchuk , 2017; A.V. Chaban, 2017; D. S. Yakovlev, 2016).

Prestige of military education and a multilevel system of training military men demands education duration increase and planning correction, cadets' initial and special parachute training volumes redistribution. All these things demand ABT system content and organization reconsideration, especially among cadets of the $1^{\text {st }}$ course, as the main stage of successful adaptation to the conditions of studying.

\section{RESEARCH METHODOLOGY}

The research was held in Tyumen Higher MilitaryEngineering Command School (military Institute) named after marshal of engineering forces A.I. Proshlyakov. First-year cadets (17-19 year-old) took part in the experimental work.

Practical value of work. Studying the degree of physical loads influence on cadets' organisms in the exercises of different effect during ABT lessons helps to control the level of tiredness and working capacity decrease, can be used for physical training of cadets in parachuting.

Practical recommendations. Special parachute training of cadets has physical and psychological orientation with stress situations revelation in terms of extreme conditions of fulfillment. It is necessary to control the volume of the load 
according to the degree of its demonstration, in order to prevent tiredness and physical working capacity decrease.

\section{RESULTS}

Scientific-methodical literature analysis according to the problem of physical loads volume and intensity planning at special parachute training lessons showed that it is necessary to reconsider the main volume of hours for optimal combination of physical loads value (small, average, big).

It is noted that special parachute training effectiveness depends on the following factors: cadets' real state of training and readiness for lessons determination; qualitative hours planning given for ABT objectives realization; continuity of the received knowledge, abilities and skills during the lessons; systematic character of the knowledge, abilities and skills of personnel development in parachute jumps improvement and training for airdrop; physical loads of different orientation planning at the lessons; control organization at all stages of training; purposeful and constant ABT methodology development; modern technical means of training use.

The difficulty of physical load planning for cadets of the $1^{\text {st }}$ course, in terms of Tyumen Higher Military-Engineering Command School (military Institute) named after marshal of engineering forces A.I. Proshlyakov, is in restriction concerning the number of hours given for special parachute training. General number of hours at the $1^{\text {st }}$ course is 36.20 hours of them are given to practical lessons, where it is senseless to speak about physical loads. During the second term there are no hours given for ABT. That is why it is necessary to create practical conditions for first year cadets to get different degree physical load

Further we present information about the degree of physical loads influence in the exercises of different orientation for the $1^{\text {st }}$ year cadets.

It is known that in sports practice physical loads are characterized according to their power of influence on an organism of those who train. Physical loads are classified as small, average, big and maximal.

The first step, small physical load, is characterized by functional systems activity intensification in an organism for the main load training.

The second step, the average physical load, is characterized by stability of motor actions and physical working capacity increase.

The third step, big physical load, is characterized by considerable functional shifts in an organism with physical working capacity level decrease in the definite time of fulfillment.

The volume of the fulfilled physical load is estimated at time, distance, the number of means repetition and also the number of hours given for the lessons.

Cadets' physical load intensity was conditioned by the speed of exercises fulfillment, time of distance and parts of the distance overcoming and the value of poundage. For cadets' parachute training physical exercises distribution was fulfilled according to the kinds of training and according to the degree of physical load.

The first kind of training is general physical training. In this kind of training the $1^{\text {st }}$ degree of the load (small) is characterized by general orientation exercises fulfillment, directed toward motor coordination development during land parachute training. It took $40 \%$ of general volume of the load. The value of the load was defined according to the indices of heart rate (HR) till 140 beats per minute.

The second degree of the load (the average) is characterized by all kinds of strength oriented exercises (with own weight, with poundage), general endurance development exercises (cross running, games, obstacle course) use during the lessons. The volume of the load takes $40 \%$ of general volume. The volume of the load is determined according to HR indices at the level of 140-160 beats per minute.

The third degree of the load (big) is characterized by all kinds of special speed oriented parachute training exercises use during the lessons, by speed endurance, special endurance development. The volume of the load takes $20 \%$ of general volume. The volume of the load is conditioned by HR indices at the level 170-180 beats per minute and can be even higher.

During different physical load fulfillment HR registration is realized for physical load fulfillment degree determination.

The second kind of training is technical and tactical training. It considers special parachute training, including land training and parachute jumps. In this kind of training the $1^{\text {st }}$ degree (small) of the load is characterized by knowledge gaining concerning parachute training and technical-tactical actions development during the jump fulfillment with paradropping in terms of training.

The second degree (the average) of the load is characterized by special parachute training of individual interaction in a group improvement.

The third degree (big) of the load is characterized by special parachute training for speed development.

Integral training of cadets in ABT includes all kinds of training in a complex. In this kind of training the $1^{\text {st }}$ step (small) of the load is characterized by the jumps fulfillment with explanation and jumps creation with mistakes correction.

The average load of the integral training includes parachute double-event competitions organization. Big load is characterized by special tasks fulfillment for speed.

At practical lessons cadets' volume of physical load in terms of special equipment and methodology absence is conditioned by the orientation of the exercises at the lessons.

\section{CONCLUSION}

Thus, in order to get necessary training effect during different orientation exercises realization at the lessons by the 
[2] Labeshchenkov O. V. Theoretical aspects of cadets' sports-technica mastery formation and development at military educational establishments of engineering profile in terms of airborne training. International scientific-practical conference "Value potential of education in shaping personality: methodology and application base" (October, 1920, 2018 Orenburg). 2018.

cadets in special parachute training the following components of physical load are taken into account:

- the orientation of exercises;

- time of exercise fulfillment;

- the degree and intensity of the load;

- general number of the fulfilled exercises;

- the interval of the rest; lessons;

- the interval of rest between the exercises and the

- the degree of physical load.

At ABT lessons of the $1^{\text {st }}$ year cadets it is necessary to use the exercises in different combination of general, partial and local influence in order to improve functional abilities of the organism systems.

The main objectives of any training should be functional abilities of an organism improvement and an optimal coordination of all systems achievement.

\section{References}

[1] Eliseev S.A. The process of cadets' professionally-applied physical training improvement. Collection of scientific works according to the materials of the II nd International scientific-practical conference "Science and education in social-cultural space sphere of modern society". Smolensk. 2017, pp. 38-39.
3] Labeshchenkov O. V. Cadets' airborne training intensification at military educational establishments. All-Russian scientific-practical conference (November, 17, 2018 Ulyanovsk). 2018.

[4] Mirzoev O.M., Maslakov V.M., Vrublevskiy E.P. Organizationalmethodical aspects of training the members of the national athletics team of Russia during winter competitive period 2007 (group of sprinters and hurdling): methodical manual. - Moscow: RSUPC (RGUFK). 2007, 8, pp. 140 .

[5] Nesterovich S. N. Physical training of border guards for the actions in extreme situations. - Moscow: Granitsa. 2005, pp. 120.

[6] Nesterovich S. N. The peculiarities of physical training among FSS border guard military men in Russia in different physical-geographical conditions. Moscow: Granitsa. 2008, pp. 12-14.

[7] Kuznetsova Z., Kuznetsov A., Mutaeva I., Khalikov G., Zakharova A Athletes preparation based on a complex assessment of functional state. In Proceedings of the $3^{\text {rd }}$ International Congress on Sport Sciences Research and Technology support. SCITEPRESS. 2015, pp. 156-160.

[8] Chaban A. V., Kuznetsova Z.M., Ryabchuk A.V. Marksmanship of cadets from military higher educational establishments on the basis of psychic processes development. Pedagogico-pshychological and medicobiological promlems of physical culture and sport. 2017, vol. 12(2), pp. 146-153. DOI 10.14526/01_2017_216.

[9] Yakovlev D. S., Volodin V.N. Physical training state at higher educational establishments of the Ministry of Defense of the Russian Federation and the ways of its development. breakthrough scientific research as the engine of science: collection of works of the International scientific-practical conference. Ufa. 2016, 226. 